\title{
Visualizing Redox Chemistry in Oxide Surfaces at Atomic-Resolution
}

\author{
M. Ek ${ }^{1}$, Q.M. Ramasse ${ }^{2}$, L. Arnarson ${ }^{1}$, P.G. Moses $^{1}$, C.F. Kisielowski ${ }^{3}$, J.R. Jinschek ${ }^{4}$, S. Helveg $^{1}$ \\ ${ }^{1 .}$ Haldor Topsoe A/S, Haldor Topsøes Allé 1, DK-2800 Kgs. Lyngby, Denmark. \\ 2. SuperSTEM Laboratory, STFC Daresbury, Keckwick Lane, Daresbury WA4 4AD, United Kingdom. \\ ${ }^{3 .}$ Lawrence Berkeley National Laboratory, The Molecular Foundry, One Cyclotron Road, Berkeley \\ California 94720, USA. \\ 4. The Ohio State University, Department of Materials Science and Engineering \& Center for Electron \\ Microscopy and Analysis (CEMAS), 1305 Kinnear Road, Columbus, Ohio 43212, USA.
}

Reduction and oxidation (redox) processes in metal-oxide surfaces play a significant role in heterogeneous catalysis. In reactive environments, the oxide surface can undergo substantial reconstruction and exchange oxygen atoms with the gas phase, and the changes in structural coordination and oxidation state of the metal ions can markedly influence the catalytic properties. These redox processes are, however, scarcely understood, reflecting a lack of atomically resolved observations of oxide surfaces under meaningful reaction conditions.

With recent advances, transmission electron microscopy has become capable of delivering atomically resolved images of catalyst in situ during exposure to reactive gas environments and elevated temperatures [1-3]. Observations of catalyst surfaces are, however, prone to alterations caused by the electron beam due to their reduced atomic coordination. Here we demonstrate that rigorous control of the electron illumination scheme is crucial for suppressing beam-induced alterations and facilitating observations of the oxide catalysts in the genuine state.

First, we address the role of electron doses and dose-rates in high-resolution transmission electron microscopy (HRTEM) of oxide catalysts. A systematic variation of the electron illumination demonstrates that low dose-rates are needed for alleviating beam-induced alterations in the oxide catalysts. Correspondingly, the HRTEM image signal reaches levels at the detection limit but can beneficially be recovered using low dose-rates in conjunction with in-line holography in order to maintain atomic-resolution and -sensitivity of the oxide surface structures (Figure 1) [2-6]. Second, we employ this concept of dose-fractionating electron detection to uncover redox properties of vanadium oxide supported on anatase titanium dioxide nanoparticles $\left(\mathrm{VO}_{\mathrm{x}} / \mathrm{TiO}_{2}\right)($ Figure 2) [6].

The $\mathrm{VO}_{\mathrm{x}} / \mathrm{TiO}_{2}$ catalyst system is widely applied for e.g. reducing $\mathrm{NO}_{\mathrm{x}}$ emissions that are harmful to human health and ecosystems. The structure-dependency of the catalytic properties has long been subject to debate, reflecting the lack of atomic-resolved images of the surface $\mathrm{VO}_{\mathrm{x}}$ phase. Specifically, we combine HRTEM and electron energy loss spectroscopy (EELS) to examine the $\mathrm{VO}_{\mathrm{x}} / \mathrm{TiO}_{2}$ catalyst under alternating reducing and oxidizing atmospheres. The observations reveal that the outermost atomic layers of the $\mathrm{VO}_{x} / \mathrm{TiO}_{2}$ catalyst underwent reversible changes in the structure and oxidation state when switching between oxidizing and reducing environments (Figure 2). That is, the $\mathrm{VO}_{\mathrm{x}}$ surface transformed between ordered and disordered states concomitant with a transition between the $\mathrm{V}(\mathrm{V})$ and $\mathrm{V}$ (III) oxidation states. Thus, the cationic sub-lattice dynamically restructured in response to oxygen exchange at the surface. Surprisingly, the $\mathrm{VO}_{\mathrm{x}}$ restructuring was found to depend on both the $\mathrm{VO}_{\mathrm{x}}$ loading and the supporting facet of the underlying $\mathrm{TiO}_{2}$. Hereby, these observations offer a first basis for rationalizing the morphology-dependent catalytic properties reported for $\mathrm{VO}_{\mathrm{x}} / \mathrm{TiO}_{2}$ catalysts . 
[1] S. Helveg, J. Catal. 328 (2015) p. 102.

[2] J.R. Jinschek and S. Helveg, Micron 43 (2012), p. 1156.

[3] S. Helveg, C.F. Kisielowski, J.R. Jinschek, P. Specht, G. Yan, H. Frei, Micron 68 (2014), p. 176.

[4] M. Ek, S.P.F. Jespersen, C.D. Damsgaard, S. Helveg, Adv. Struct. Chem. Imag. (2016), p. 2:4.

[5] C. Kisielowski, H. Frei, P. Specht, I.D. Sharp, J.A. Haber, S. Helveg, Adv. Struct. Chem. Imag. (2016), p. 2:13.

[6] M. Ek, Q.M. Ramasse, L. Arnarson, P.G. Moses, S. Helveg, under review (2017).

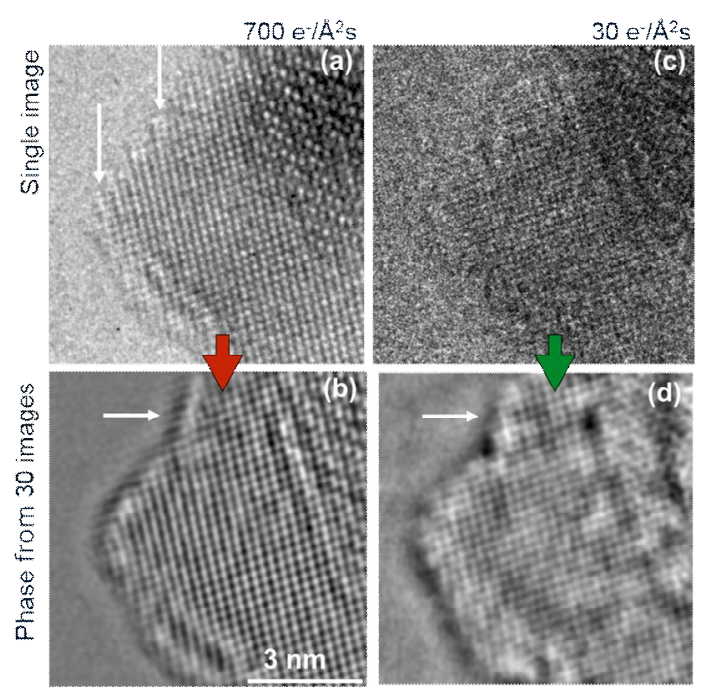

Figure 1. Effect of electron illumination on surface structure and dynamics. (a, c) Single HRTEM images of $\mathrm{Co}_{3} \mathrm{O}_{4}$. (b,d) Phase images of $\mathrm{Co}_{3} \mathrm{O}_{4}$ from reconstructed exit wave functions. All images obtained in 2.1 mbar CO. The dose-rates are vastly different $\left(700 \mathrm{e}^{-} \AA^{-2} \mathrm{~s}^{-1}\right.$ in $\mathrm{a}, \mathrm{b}$ and $30 \mathrm{e}^{-} \AA^{-2} \mathrm{~s}^{-1}$ in $\left.\mathrm{c}, \mathrm{d}\right)$. Arrows emphasize a streaky contrast at the high dose-rate in (b) which is absent at the low dose-rate in (d). This streaky contrast is therefore attributed to beam-induced atom displacements. From [3].
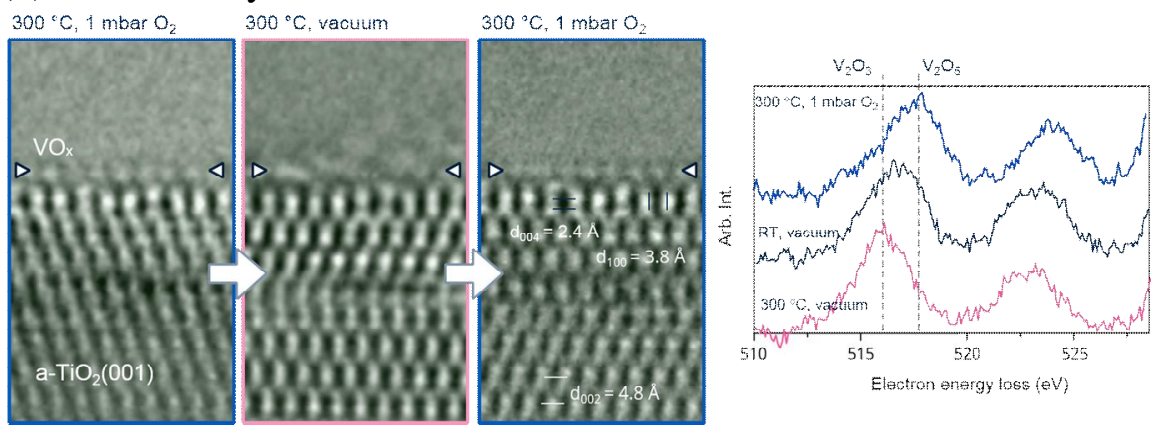

Figure 2. Reversible redox changes in a $\mathrm{VO}_{\mathrm{x}} / \mathrm{TiO}_{2}$ catalyst surface. (a-c) Exit wave phase images of the $\mathrm{VO}_{\mathrm{x}}$ surface layer of the catalyst under alternating oxidizing $\left(300^{\circ} \mathrm{C}, 1 \mathrm{mbar} \mathrm{O}_{2}\right)$ and reducing $(300$ ${ }^{\circ} \mathrm{C}$, vacuum) conditions. (d) Electron energy loss spectra from an agglomerate of several $\mathrm{VO}_{\mathrm{x}} / \mathrm{TiO}_{2}$ particles shows the V oxidation state correspondingly alternate between V(III) and V(V). From [6]. 